\title{
Interior Design Research of Spatial Order based on 3DS Studio Max
}

\author{
Mingming Xu, Minmin Guo
}

Zaozhuang University, Zaozhuang city, Shandong Province, 277100, China

\section{Keywords: Form, space, array}

\begin{abstract}
Interior space plane layout and spatial analysis play an important role in the design process. This paper, based on the analysis of form, shape, size, color and texture, organizes the relation between form and spatial array and explains well the architecture and interior spatial order based on 3DS Studio Max.
\end{abstract}

\section{Introduction}

In recent ten years, courses related with interior design, landscape design and 3DS Max keep being taught, meanwhile, people are constantly considering to expand the design courses[1]. This paper, from the perspective of 3DS Studio Max spatial order, analyzes the spatial order of interior home furnishings, followed by summarizing the role of home furnishing plane layout, spatial analysis and flow line in the whole interior design[2]. Also, it conducts construction analysis on the interior spatial order based on basic constitution laws including symmetry, balance, repeat, white space and unification, etc. American architect Dai-Kam Ching explained the relation among form, space, array, traffic, ratio and dimension in the Architecture: Form, Space, \& Order, analyzing the architecture form and space composition from the perspective of geometric figure and aesthetics basic principles[3].

"Form" in design process refers to the structure and array way among objects or the basic internal elements within object[4]. Also it confirms if the form and layout conform to the principle of balance, contrast, exaggeration and rhythm, etc. The shape, size, color, texture and location all impact the form. First the shape is analyzed. Shape: The shape modeling in interior design field and the appearance of 3DS Studio Max ensures us to simulate the real space, thus the size and dimension in real life can be shown veritably[5]. The basic shape of interior space is defined by related tools of Command Panel of 3DS Studio Max (hereafter referred to as Max). The Max command panel provides some tool panels to create geometry and stereogram. The selection and conversion of "body" and "line" ensures the control on object shape. Yet this is just the beginning of moulding spaces. The moulding of furniture in interior space pertains to or is the derivation of the basic shape of objects, with the furniture style determining the shape. From the well-known chair in the period of Ming and Qing Dynasty to simplified European furniture, then to the furniture characteristics of Baroco style and Rococo style, it can be seen that the shape change of furniture also reflects the political and cultural development trend in the society at that time. On that account, compared with color, texture and other elements, the value of shape in the whole spatial order can not be underestimated. Size: Size is used to defined the shape. The Max system has set up a very detailed data system which can meet the accuracy requirement of object and space simulation. Generally speaking, shape and size run synchronously in the spatial order. "Shape" determines the "circumference" of object and "size” regulates its “dimension" . In interior space, furniture with same moulding can present different visual effects when the size changes a little. The conversion of dimension and circumference effectively change the rhythm of the whole space. Color: As the first visual element in architecture and interior space, color can be effectively used to differentiate space object from environment. The threshold value of hue and saturability control the color lightness and purity of object and whole space. Also, color impacts the improvement of visual weight of form. In building spatial order, the reasonable selection and use of color can effectively expand and define the space effect. The selection of furniture color in interior space needs great attention, saying hue except white and black shall be controlled within three to four sets (partial area can be embellished with 
color lumps of small size with the ratio and dimension of color lumps being controlled). Max system provides complete color matching plans for the color adjustment where wispy color difference can achieve ideal effect. Texture: In design courses, texture mainly refers to the feeling that material or the whole work brings to people. Different from color, textures stress more on the psychological effect to individuals. To better embody the texture, Max system sets up strong texture parameter system, bringing people huge visual impact via simulating the texture of real objects in life in the three-dimensional space. As a result, the presenting effects of texture can be compared favorably with real object. Location: The sense of form of the whole space will change according to the different location of viewers. During the construction of interior spatial order, reasonable division of furnishing locations (in plane) impacts the subsequent filament line of the whole space. The built-in camera chain in Max system serves for the spatial location setting, especially that the physical camera in the vary plug-in is able to set the depth of field and select the best angle of landscape and interior space. Of course, besides the elements above mentioned, the orientation of people or objects and the visual inertia are also variable factors. The changeable visual angle, distance and ray of light can impact our observation form.

The increase or decrease in shape controls the change of form, i.e, the addition or subtraction made based on basic entities like square, cuboid, cylinder, sphere, etc. means the change of form. "People will see different architecture elements when enter into the architecture. Various architecture forms leap to the eyes when looking look around. The naughty sunshine forms shadow or umbra like mist in the wall. People can see the outside standing in the front entrance where allows people to further fell the architecture order. " The famous French architect Le Corbusier designed the Villa La Roche-Jeanerette (also called Maison La Roche) in 1923, which was considered the pathfinder of “white era” . The Maison La Roche refers to office space with business nature and the Maison Jeanerette is a common residential architecture. The whole architecture and interior space fully uses the addition and accumulation constitution method, highlighting the gallery space via arc in order to differentiate balcony and lobby. The application of light, the ratio of length, width and height of wall, architecture material and color matching are deeply considered. The roof deck in the second floor adopts subduction method from the Four Residence Shape, which fulfills the demand of external architecture with the interior functionality being considered. The subduction increases the space volume. The increase in shapes means that new forms are added to the main bodies, which reflects the harmonious and unified relation between main body and subsidiary components. Each space division in the architecture has its specific meaning, showing the full respect on human living demand. This architecture stands for the essence of design theory of Le Corbusier in his later years. His unique opinion on constitution method also impacts his subsequent architecture style. Chapelle De Ronchamp was established in 1955. The design of facade window aperture outside the church was impacted by the form of "cutting" , with the windows in walls of different sizes and arrangement, breaking the mindset to church architectures and making the architecture a miracle in church architectural history. Meanwhile, the appearance color is still white, contributing to an unique label in architectural history. Max system is frequently used to practice the addition or subduction architecture form via basic modeling or entity modification modeling. The basic modeling can be achieved based on the addition and reduction of lines combined with the EXtrude command in the modification command panel. The structure of gallery in the plane graph of second floor of Maison La Roche adopts this method, dividing line segment layers guided by the linear Line command and setting the gallery height according to EXtrude command or using Proboolean to calculate the desirable shape based on three dimensional entity. This method improves the simulation efficiency of architecture and interior spatial order and provides important technical support for the construction of spatial space structure framework of isolated architecture and clustered architectures. The addition, accumulation and subduction constitution methods provide good reference for the later architecture design, which can embody the expansion or shrink of spatial quickly via Max system.

Charles Moore mentioned in the The Place Houses that to build a good house needs the improvement of human' $s$ awareness and the leap from simple house construction to the overall 
appearance structure, including the array way of different parts. There are many spatial constitution ways: Interspersed space, adjoining space, space inside space and space linked by public space. Interspersed space: A shared space can be formed via the crossing of two spaces. Besides the shared space, the two spaces maintain their own function. Adjoining space means that the two spaces are adjoined. Generally, there shall be corresponding partitions, walls, cylinder or platform, etc. in the middle of the adjoined spaces to differentiate the two adjoined spaces. Adjoining space is the most common in living units. Space inside space: Large space contains small space and the two spaces are unified in form. Sometimes the spatial form of the two spaces may be distinguished to tell their functionality. For example, when large public space contains meeting room, we can say square contains round space in the aspect of form and the continuity and unification shall be ensured in the total space process. Space linked by public space: Space A is linked with Space B through Space C. Space C plays as the transition tool. The form of transition space is decided by the residual space of two relevant spaces. New architecture form and reasonable space effect have been achieved during the Max modeling process after the crossing, relevance and integration of spatial relationship including the overall spatial framework and the spatial contrast of architecture construction unit. There are many spatial array forms, including centralized array centered main body, coordinating relation-based linear array, emanant array out-diffusing from central point, net-type array, clustered array, etc. Centralized array stresses on the dominant role of center space. The whole spatial form is in order. It is mainly composed by some graphs with different forms. Besides the main body, other forms enjoy different ratio and size. Many European church architecture spaces are the representatives of centralized array, among which the St. Sophia Cathedral in Istanbul and Taj Mahal Mausoleum in India are famous.

\section{Conclusions}

Space is based on the shape, size, color, texture and location of objects and the increase or decrease in form impacts the spatial order of architecture. The 3DS Studio Max can be used to better control the rhythm sensation of architecture space and interior space and provide technical support for the further research, resulting in a significant role in architecture and interior design.

\section{Acknowledgement}

Phased Objectives of 2015 Educational Reform Project Approval of Zaozhuang University

\section{References}

[1] Zhou J Z, Han L Q, Xu X P, et al. Research of Model-Constructing Method for Bulldozer Case Based on NURBS. Applied Mechanics \& Materials, 487, pp. 389-393, 2014.

[2] Vusić D. 3ds Studio Max - Particle Animation with pFlow and Krakatoa System. Tehnič ki Glasnik, 7, pp. 391-398, 2013.

[3] MAX J. EGENHOFER, ROBERT D. FRANZOSA. Point-set topological spatial relations. International Journal of Geographical Information Science, 5(2), pp. 161-174, 1991.

[4] Liu, Tai-Ping, Yu, et al. DIRICHLET-NEUMANN KERNEL FOR HYPERBOLIC-DISSIPATIVE SYSTEM IN HALF-SPACE. Bull.inst.math.acad.sin, 2012(4), pp. 477-543, 2012.

[5] Delgado F, Martínez R, Puche J, et al. Towards a client-oriented integration of construction processes and building GIS systems. Computers in Industry, 73(October), pp. 51-68, 2015. 